\title{
Risk Factors for Thyroid Cancer: A Hospital-Based Case-Control Study in Korean Adults
}

\author{
Seung-Kwon Myung, $\mathrm{MD}, \mathrm{PhD}^{1,2,3,4}$ \\ Chan Wha Lee, MD ${ }^{2,5}$ \\ Jeonghee Lee, MS ${ }^{4}$ \\ Jeongseon Kim, $\mathrm{PhD}^{1,4}$ \\ Hyeon Suk Kim, $\mathrm{PhD}^{6}$
}

${ }^{1}$ Department of Cancer Control and Policy, Graduate School of Cancer Science and Policy, National Cancer Center, Goyang,

${ }^{2}$ Center for Cancer Prevention and Detection, National Cancer Center Hospital, National Cancer Center, Goyang, ${ }^{3}$ Department of Family Medicine, National Cancer Center Hospital, National Cancer Center, Goyang, ${ }^{4}$ Molecular Epidemiology Branch, Research Institute, National Cancer Center, Goyang, ${ }^{5}$ Department of Radiology, Center for Diagnostic Oncology, National Cancer Center Hospital, National Cancer Center, Goyang, ${ }^{6}$ School of Nursing, Shinhan University, Dongducheon, Korea

Correspondence: Chan Wha Lee, MD Department of Radiology, Center for Diagnostic Oncology, National Cancer Center Hospital,

National Cancer Center, 323 Ilsan-ro, Ilsandong-gu, Goyang 10408, Korea Tel: 82-31-920-2639

Fax: 82-31-920-2606

E-mail: cwlee@ncc.re.kr

Co-correspondence: Jeongseon Kim, $\mathrm{PhD}$ Department of Cancer Control and Policy, Graduate School of Cancer Science and Policy, National Cancer Center, 323 Ilsan-ro, Ilsandong-gu, Goyang 10408, Korea Tel: 82-31-920-2570

Fax: 82-31-920-2579

E-mail: jskim@ncc.re.kr

Received August 17, 2015

Accepted June 6, 2016

Published Online June 23, 2016

\section{Purpose}

Although the incidence of thyroid cancer in Korea has rapidly increased over the past decade, few studies have investigated its risk factors. This study examined the risk factors for thyroid cancer in Korean adults.

\section{Materials and Methods}

The study design was a hospital-based case-control study. Between August 2002 and December 2011, a total of 802 thyroid cancer cases out of 34,211 patients screened from the Cancer Screenee. Cohort of the National Cancer Center in South Korea were included in the analysis. A total of 802 control cases were selected from the same cohort, and matched individually (1:1) by age ( \pm 2 years) and area of residence for control group 1 and additionally by sex for control group 2 .

\section{Results}

Multivariate conditional logistic regression analysis using the control group 1 showed that females and those with a family history of thyroid cancer had an increased risk of thyroid cancer, whereas ever-smokers and those with a higher monthly household income had a decreased risk of thyroid cancer. On the other hand, the analysis using control group 2 showed that a family history of cancer and alcohol consumption were associated with a decreased risk of thyroid cancer, whereas higher body mass index (BMI) and family history of thyroid cancer were associated with an increased risk of thyroid cancer.

\section{Conclusion}

These findings suggest that females, those with a family history of thyroid cancer, those with a higher BMI, non-smokers, non-drinkers, and those with a lower monthly household income have an increased risk of developing thyroid cancer.

\section{Key words}

Thyroid neoplasms, Smoking, Alcohols, Risk factors, Case-control studies 


\section{Introduction}

According to the World Cancer Report 2014, thyroid cancer is one of the less frequent cancers worldwide [1]. Its incidence, however, has increased almost two-fold over the past few decades, due mainly to the increased detection of thyroid cancer using thyroid ultrasonography [1,2]. In particular, the incidence rate of thyroid cancer in South Korea in 2011 was 15 times higher than in 1993 [3].

Although the precise causes of thyroid cancer remain unclear, a few risk factors, such as exposure to radiation, sex (women), and a diet low in iodine (follicular thyroid cancer) are known to increase the risk of thyroid cancer [4]. Recently, several lifestyle factors have been suggested to have an association with the risk of developing thyroid cancer from the findings of observational studies. According to Schmid et al.'s meta-analysis [5] of case-control and cohort studies in 2013 , there was no overall significant association between physical activity and thyroid cancers, even though subgroup analyses revealed inconsistent findings according to the study design. In 2012, Zhao et al. [6] reported that overweight and obesity increased the risk of thyroid cancer significantly (by 18\%) from the findings of a meta-analysis of seven cohort studies. On the contrary, unlike other cancers, a pooled analysis of five prospective studies in the United States suggested that cigarette smoking and alcohol consumption were associated with a decreased risk of thyroid cancer [7]. In addition, Cho and Kim [8] reported that the risk of thyroid cancer was decreased by $21 \%$ in ever-smokers compared to never-smokers when they performed a metaanalysis of 31 observational studies [8].

As described before, the age-standardized incidence of thyroid cancer in Korea women $(88.6$ per 100,000$)$ has increased rapidly and is the highest among all countries in the world (20 per 100,000 for the United States, 12.7 for Australia, and 6.1 per 100,000 for world) [9]. Despite this, few studies have reported the risk factors for thyroid cancer in Korean adults. Moreover, the sample sizes of previous casecontrol studies on this issue were small.

This study examined the risk factors for thyroid cancer in Korean adults using a hospital-based case-control study.

\section{Materials and Methods}

\section{Study population}

A large hospital-based case-control study was conducted using the data from the Cancer Screenee Cohort of the
National Cancer Center in South Korea. All participants were men and women aged between 30 and 70 years, who underwent health screening examinations including thyroid ultrasonography. All the participants were asked to complete a self-administered questionnaire about their sociodemographic characteristics (e.g., age, education, occupation, household income, and marital status), cigarette smoking habits, alcohol drinking habits, and their regular exercise habits. A total of 34,211 participants provided written informed consent for study participation between August 2002 and December 2011.

\section{Case and control selection}

The thyroid cancer cases were defined based on the International Classification of Diseases for Oncology (ICD-O) (code C73) and were ascertained by a linkage to the Korea Central Cancer Registry (KCCR) database, which has been used to identify the incidence of cancer in Korea. Among the 828 thyroid cancer patients, a total of 802 patients were finally selected after excluding those who did not answer the questionnaire.

The controls were selected from the same cohort with 34,211 participants, who underwent health screening examinations including thyroid ultrasonography. Among the potential controls $(n=31,453)$ who were not diagnosed with any cancer including thyroid cancer, 2,962 participants were excluded due to missing questionnaires or insufficient information on their residential areas. From the remaining 28,491 participants, using an incidence density sampling method, one control was selected randomly for each thyroid cancer case from the appropriate risk sets consisting of all study participants, free of cancer. Those in control group 1 were matched individually to the cases according to age (within 2 years) and residential area (Seoul, Gyeonggi, Gangwon, Chungcheong, Jeolla, Gyeongsang, Jeju, North America, and other Asian countries). In control group 1, sex was not included as a matching variable to determine if sex is associated with the risk of thyroid cancer. In addition, the controls for control group 2 were matched to cases by age (within 2 years), residential areas Seoul, Gyeonggi, Gangwon, Chungcheong, Jeolla, Gyeongsang, Jeju, North America, and other Asian countries), and also sex to reduce the confounding effect of sex. A total of 802 incident cases and 802 controls were included for the final analysis. The study procedure including the linkage to the KCCR database was approved by the institutional review board of the National Cancer Center (NCC2014-0096).

\section{Statistical methods}

To assess the association between the risk factors and thy- 
roid cancer, conditional logistic regression models were used to calculate the odds ratios (ORs) and 95\% confidence intervals (CIs) using univariate and multivariate analyses. The multivariate conditional logistic regression models were adjusted for sex (female vs. male), body mass index (BMI, $\mathrm{kg} / \mathrm{m}^{2}:<23,23-25, \geq 25$ ), family history of cancer (first degree relative: yes vs. no), family history of thyroid cancer (first degree relative: yes vs. no), education (college or above, high school vs. middle school or below), occupation (agriculture/ laborer/unemployed/others, sales/service, profession/ office worker vs. housewife), monthly household income ( $>\$ 3,706$ or $\$ 1,853-\$ 3,706$ vs. $<\$ 1,853$ ), marital status (divorced/widowed, unmarried vs. married), alcohol consumption (ever-drinker, current drinker, former drinker vs. nondrinker), and smoking status (ever-smoker, current smoker, former smoker vs. non-smoker). In addition, the CochranArmitage test for trend was conducted to investigate the relationship between increasing exposure to smoking and thyroid cancer risk. All the analyses were performed for both control groups 1 and 2. The goodness of fit of a model was measured by the generalized $\mathrm{R}^{2}$ statistic that Allison discussed [10] as follows:

$$
\mathrm{R}^{2}=1-\mathrm{e}^{-(\mathrm{LRT} / \mathrm{n})}
$$

, where likelihood ratio test statistic (LRT) $=-2 \log L(0)$ $[-2 \log \mathrm{L}(\mathrm{p})], \mathrm{n}$ is the sample size, $\log \mathrm{L}(0)$ is the $\log$-likelihood for a null model with no covariates, and $\log \mathrm{L}(\mathrm{p})$ is the $\log$ likelihood for the fitted model with $p$ covariates. All statistical analyses were performed using SAS ver. 9.3 software (SAS Institute Inc., Cary, NC).

\section{Results}

Table 1 lists the distribution of the general characteristics among the 1,604 participants with thyroid cancer $(n=802)$ and control cases $(\mathrm{n}=802)$ in the control group 1 according to sex, BMI, family history of cancer, family history of thyroid cancer, education, occupation, monthly household income, marital status, alcohol consumption, and smoking status. In univariate analysis, females (OR, 2.97; 95\% CI, 2.38 to 3.71), family history of thyroid cancer (OR, 3.64; $95 \%$ CI, 1.87 to 7.09 ), and divorced or widowed (OR, 2.38; 95\% CI, 1.54 to 3.67) were associated with an increased risk of thyroid cancer, whereas a family history of cancer, higher education levels, other occupations (other than housewife), higher monthly household incomes, alcohol consumption, and eversmokers were associated with a decreased risk of thyroid cancer (Table 1).
Table 1 also lists the findings from multivariate conditional logistic regression analysis adjusted for sex, BMI, family history of cancer, family history of thyroid cancer, education, occupation, monthly household income, marital status, alcohol consumption, and smoking status. The results showed that females (OR, 2.08; 95\% CI, 1.26 to 3.45$)$ and a family history of thyroid cancer (OR, 4.39; 95\% CI, 1.73 to 11.15) were more likely to have an increased risk of thyroid cancer, whereas higher household incomes (> \$3,706 vs. $<\$ 1,853$; OR, 0.59 ; $95 \%$ CI, 0.36 to 0.98$)$ and ever-smokers (OR, $0.62 ; 95 \% \mathrm{CI}, 0.44$ to 0.86 ) were more likely to have a decreased risk of thyroid cancer. On the other hand, there was no significant association observed with BMI, family history of cancer, education levels, occupational, marital status, and alcohol consumption.

In multivariate conditional logistic regression analysis according to the smoking history, compared to non-smokers, there was a dose-response relationship in the ever-smokers between the years of cigarette smoking and a decreased risk of thyroid cancer (OR, $0.87 ; 95 \% \mathrm{CI}, 0.50$ to 1.50 for $\leq 10$ years; OR, $0.61 ; 95 \%$ CI, 0.39 to 0.95 for $11-20$ years; OR, $0.59 ; 95 \%$ CI, 0.37 to 0.95 for $21-30$ years; OR, $0.62 ; 95 \%$ CI, 0.35 to 1.10 for $>30$ years; $p$-value for trend $=0.019$ ) (Table 2). On the other hand, no dose-response relationship was observed for the age when they started to smoke and the number of daily cigarette smoking.

Table 3 lists the general characteristics of the study participants with the same case group and the control group 2 in univariate analysis and multivariate conditional logistic regression analysis. In multivariate conditional logistic regression analysis, a family history of cancer and alcohol consumption were associated with a decreased risk of thyroid cancer, whereas a higher BMI and a family history of thyroid cancer were associated with an increased risk of thyroid cancer. Unlike the findings from multivariate analysis using control group 1, smoking was not associated with a risk of thyroid cancer.

\section{Discussion}

This hospital-based case-control study found that females and those with a family history of thyroid cancer had an increased risk of thyroid cancer. In contrast, ever-smokers and those with higher household incomes were more likely to have a lower risk of thyroid cancer. In particular, an inverse dose-response association was observed between the years of cigarette smoking and the thyroid cancer risk. When the analysis was performed using the control group matched by sex as well as age and residential areas, alcohol consump- 
Table 1. General characteristics of the study participants with the control group 1 in univariate analysis and multivariate conditional logistic regression analysis

\begin{tabular}{|c|c|c|c|c|}
\hline Variable & $\begin{array}{c}\text { Control }^{a)} \\
(n=802)\end{array}$ & $\begin{array}{c}\text { Case } \\
(n=802)\end{array}$ & $\begin{array}{c}\text { Crude OR } \\
(95 \% \mathrm{CI})\end{array}$ & $\begin{array}{c}\text { Adjusted OR } \\
(95 \% \mathrm{CI})^{\mathrm{b})}\end{array}$ \\
\hline \multicolumn{5}{|l|}{ Sex } \\
\hline Male & $432(53.9)$ & $229(28.6)$ & 1.00 & 1.00 \\
\hline Female & $370(46.1)$ & $573(71.5)$ & $2.97(2.38-3.71)$ & $2.08(1.26-3.45)$ \\
\hline \multicolumn{5}{|l|}{ BMI $\left(\mathrm{kg} / \mathrm{m}^{2}\right)$} \\
\hline$<23$ & $307(38.3)$ & $309(38.5)$ & 1.00 & 1.00 \\
\hline $23-25$ & $218(27.2)$ & $221(27.6)$ & $1.01(0.79-1.29)$ & $1.21(0.85-1.72)$ \\
\hline$>25$ & $277(34.5)$ & $272(33.9)$ & $0.98(0.77-1.23)$ & $1.23(0.88-1.72)$ \\
\hline \multicolumn{5}{|l|}{ Family history of cancerc) } \\
\hline No & $211(26.3)$ & $246(30.7)$ & 1.00 & 1.00 \\
\hline Yes & $585(72.9)$ & $543(67.7)$ & $0.79(0.63-0.99)$ & $0.74(0.54-1.02)$ \\
\hline Missing & $6(0.8)$ & $13(1.6)$ & & \\
\hline \multicolumn{5}{|l|}{ Family history of thyroid cancerc) } \\
\hline No & $785(97.9)$ & $748(93.3)$ & 1.00 & 1.00 \\
\hline Yes & $11(1.4)$ & $41(5.1)$ & $3.64(1.87-7.09)$ & $4.39(1.73-11.15)$ \\
\hline Missing & $6(0.8)$ & $13(1.6)$ & & \\
\hline \multicolumn{5}{|l|}{ Education } \\
\hline Middle school or below & $121(15.1)$ & $139(17.3)$ & 1.00 & 1.00 \\
\hline High school & $263(32.8)$ & $260(32.4)$ & $0.82(0.60-1.12)$ & $1.06(0.66-1.69)$ \\
\hline College or above & $409(51.0)$ & $350(43.6)$ & $0.67(0.49-0.92)$ & $1.19(0.72-1.97)$ \\
\hline Missing & $9(1.1)$ & $53(6.6)$ & & \\
\hline \multicolumn{5}{|l|}{ Occupation } \\
\hline Housewife & $228(28.4)$ & $349(43.5)$ & 1.00 & 1.00 \\
\hline Profession/Office worker & $329(41.0)$ & $229(28.6)$ & $0.46(0.36-0.59)$ & $1.11(0.26-1.76)$ \\
\hline Sales/Service & $122(15.2)$ & $100(12.5)$ & $0.55(0.40-0.76)$ & $1.07(0.66-1.71)$ \\
\hline Agriculture/Laborer/Unemployed/Others & $114(14.2)$ & $80(10.0)$ & $0.47(0.32-0.66)$ & $0.99(0.56-1.76)$ \\
\hline Missing & $9(1.1)$ & $44(5.5)$ & & \\
\hline \multicolumn{5}{|l|}{ Monthly household income } \\
\hline$<\$ 1,853^{\mathrm{d})}$ & $82(10.2)$ & $107(13.3)$ & 1.00 & 1.00 \\
\hline$\$ 1,853-\$ 3,706$ & $221(27.6)$ & $224(27.9)$ & $0.65(0.44-0.97)$ & $0.72(0.44-1.19)$ \\
\hline$>\$ 3,706$ & $429(53.5)$ & $329(41.0)$ & $0.49(0.33-0.71)$ & $0.59(0.36-0.98)$ \\
\hline Missing & $70(8.7)$ & $142(17.7)$ & & \\
\hline \multicolumn{5}{|l|}{ Marital status } \\
\hline Married & $741(92.4)$ & $674(84.0)$ & 1.00 & 1.00 \\
\hline Unmarried & $26(3.2)$ & $25(3.1)$ & $1.01(0.55-1.87)$ & $0.70(0.31-1.62)$ \\
\hline Divorced/Widowed & $35(4.4)$ & $74(9.2)$ & $2.38(1.54-3.67)$ & $1.67(0.87-3.22)$ \\
\hline Missing & 0 & $29(3.6)$ & & \\
\hline \multicolumn{5}{|l|}{ Alcohol consumption } \\
\hline Non-drinker & $236(29.4)$ & $360(44.9)$ & 1.00 & 1.00 \\
\hline Former drinker & $30(3.7)$ & $45(5.6)$ & $1.05(0.63-1.76)$ & $1.79(0.87-3.71)$ \\
\hline Current drinker & $520(64.8)$ & $373(46.5)$ & $0.46(0.36-0.57)$ & $0.92(0.66-1.30)$ \\
\hline Ever-drinker & $550(49.0)$ & $418(25.7)$ & $0.50(0.40-0.61)$ & $0.81(0.63-1.06)$ \\
\hline Missing & $16(2.0)$ & $24(3.0)$ & & \\
\hline
\end{tabular}


Table 1. Continued

\begin{tabular}{|c|c|c|c|c|}
\hline Variable & $\begin{array}{l}\text { Controla) }^{a} \\
(n=802)\end{array}$ & $\begin{array}{c}\text { Case } \\
(n=802)\end{array}$ & $\begin{array}{c}\text { Crude OR } \\
(95 \% \text { CI) }\end{array}$ & $\begin{array}{c}\text { Adjusted OR } \\
(95 \% \mathrm{CI})^{\mathrm{b})}\end{array}$ \\
\hline \multicolumn{5}{|l|}{ Smoking status } \\
\hline Non-smoker & $382(47.6)$ & $547(68.2)$ & 1.00 & 1.00 \\
\hline Former smoker & $178(22.2)$ & 109 (13.6) & $0.43(0.33-0.58)$ & $0.75(0.48-1.17)$ \\
\hline Current smoker & $215(26.8)$ & 97 (12.1) & $0.29(0.22-0.40)$ & $0.49(0.31-0.78)$ \\
\hline Ever-smoker & $393(49.0)$ & $206(25.7)$ & $0.34(0.27-0.43)$ & $0.62(0.44-0.86)$ \\
\hline Missing & $27(3.4)$ & $49(6.1)$ & & \\
\hline
\end{tabular}

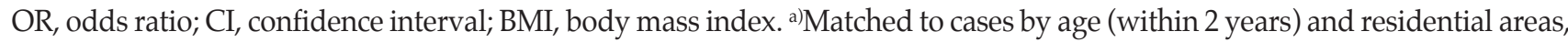

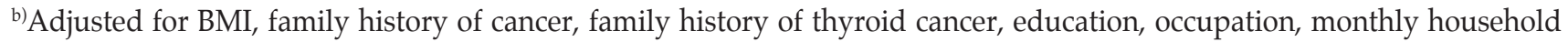
income, marital status, alcohol consumption, and smoking status; $R^{2}=0.1277$, c)First degree relatives, ${ }^{d} \$ 1=1,079$ Korean won (as of April 26, 2015).

Table 2. Association between the risk of thyroid cancer and smoking history, such as age at starting to smoke, years of cigarette smoking, and number of daily cigarette smoking in multivariate conditional logistic regression analysis

\begin{tabular}{|c|c|c|c|c|}
\hline Variable & $\begin{array}{l}\text { Control } \\
(n=802)\end{array}$ & $\begin{array}{c}\text { Case } \\
(n=802)\end{array}$ & $\begin{array}{c}\text { Crude OR } \\
(95 \% \text { CI) }\end{array}$ & $\begin{array}{c}\text { Adjusted OR } \\
(95 \% \mathrm{CI})^{\mathrm{a})}\end{array}$ \\
\hline \multicolumn{5}{|c|}{ Age at starting to smoke } \\
\hline Never smoking & $382(47.6)$ & $547(68.2)$ & 1.00 & 1.00 \\
\hline$\leq 18$ & $74(9.2)$ & $31(3.9)$ & $0.26(0.17-0.42)$ & $0.52(0.29-0.93)$ \\
\hline $19-24$ & $223(27.8)$ & $121(15.1)$ & $0.36(0.28-0.48)$ & $0.76(0.52-1.12)$ \\
\hline$\geq 25$ & $54(6.7)$ & $28(3.5)$ & $0.38(0.23-0.62)$ & $0.57(0.33-1.01)$ \\
\hline Missing & $69(8.6)$ & $75(9.4)$ & & \\
\hline $\mathrm{p}$-value for trend & & & $<0.001$ & 0.133 \\
\hline \multicolumn{5}{|c|}{ Years of cigarette smoking } \\
\hline Never smoking & $382(47.6)$ & $547(68.2)$ & 1.00 & 1.00 \\
\hline$\leq 10$ & $40(5.0)$ & $34(4.2)$ & $0.60(0.37-0.99)$ & $0.87(0.50-1.50)$ \\
\hline $11-20$ & $122(15.2)$ & $58(7.2)$ & $0.33(0.23-0.47)$ & $0.61(0.39-0.95)$ \\
\hline $21-30$ & $128(16.0)$ & $62(7.7)$ & $0.30(0.20-0.43)$ & $0.59(0.37-0.95)$ \\
\hline$>30$ & $71(8.9)$ & $29(3.6)$ & $0.29(0.18-0.47)$ & $0.62(0.35-1.10)$ \\
\hline Missing & $59(7.4)$ & $72(9.0)$ & & \\
\hline $\mathrm{p}$-value for trend & & & $<0.001$ & 0.019 \\
\hline \multicolumn{5}{|l|}{ No. of cigarettes/day } \\
\hline Never smoking & $382(47.6)$ & $547(68.2)$ & 1.00 & 1.00 \\
\hline$\leq 10$ & $110(13.7)$ & $58(7.2)$ & $0.35(0.25-0.50)$ & $0.61(0.40-0.93)$ \\
\hline $11-20$ & $180(22.4)$ & $101(12.6)$ & $0.39(0.29-0.52)$ & $0.84(0.56-1.26)$ \\
\hline $21-30$ & $48(6.0)$ & $16(2.0)$ & $0.23(0.12-0.41)$ & $0.42(0.22-0.82)$ \\
\hline$>30$ & $25(3.1)$ & $11(1.4)$ & $0.27(0.13-0.56)$ & $0.61(0.26-1.42)$ \\
\hline Missing & $57(7.1)$ & $69(8.6)$ & & \\
\hline $\mathrm{p}$-value for trend & & & $<0.001$ & 0.071 \\
\hline
\end{tabular}

OR, odds ratio; CI, confidence interval. a)Adjusted for sex, body mass index, family history of cancer, family history of thyroid cancer, education, occupation, monthly household income, marital status, smoking status, and alcohol consumption; $\mathrm{R}^{2}=0.1070$. 
Table 3. General characteristics of the study participants with the control group 2 in univariate analysis and multivariate conditional logistic regression analysis

\begin{tabular}{|c|c|c|c|c|}
\hline Variable & $\begin{array}{c}\text { Control }^{a)} \\
(n=802)\end{array}$ & $\begin{array}{c}\text { Case } \\
(n=802)\end{array}$ & $\begin{array}{c}\text { Crude OR } \\
(95 \% \mathrm{CI})\end{array}$ & $\begin{array}{c}\text { Adjusted OR } \\
(95 \% \mathrm{CI})^{\mathrm{b})}\end{array}$ \\
\hline \multicolumn{5}{|l|}{ Sex } \\
\hline Male & $229(28.6)$ & $229(28.6)$ & - & - \\
\hline Female & $573(71.5)$ & $573(71.5)$ & - & - \\
\hline \multicolumn{5}{|l|}{ BMI $\left(\mathrm{kg} / \mathrm{m}^{2}\right)$} \\
\hline$<23$ & $353(44.0)$ & $309(38.5)$ & 1.00 & 1.00 \\
\hline $23-25$ & $225(28.1)$ & $221(27.6)$ & $1.14(0.89-1.46)$ & $1.28(0.98-1.68)$ \\
\hline$>25$ & $224(27.9)$ & $272(33.9)$ & $1.11(1.11-1.80)$ & $1.42(1.09-1.85)$ \\
\hline \multicolumn{5}{|l|}{ Family history of cancer ${ }^{c)}$} \\
\hline No & $187(23.3)$ & $246(30.7)$ & 1.00 & 1.00 \\
\hline Yes & $606(75.6)$ & $543(67.7)$ & $0.66(0.52-0.83)$ & $0.63(0.49-0.81)$ \\
\hline Missing & $9(1.1)$ & $13(1.6)$ & & \\
\hline \multicolumn{5}{|l|}{ Family history of thyroid cancerc) } \\
\hline No & $787(98.1)$ & $748(93.3)$ & 1.00 & 1.00 \\
\hline Yes & $6(0.8)$ & $41(5.1)$ & $8.00(3.16-20.27)$ & $9.41(3.61-24.51)$ \\
\hline Missing & $9(1.1)$ & $13(1.6)$ & & \\
\hline \multicolumn{5}{|l|}{ Education } \\
\hline Middle school or below & $159(19.8)$ & $139(17.3)$ & 1.00 & 1.00 \\
\hline High school & $276(34.4)$ & $260(32.4)$ & $1.08(0.80-1.45)$ & $1.19(0.86-1.66)$ \\
\hline College or above & $353(44.0)$ & $350(43.6)$ & $1.15(0.85-1.57)$ & $1.29(0.90-1.86)$ \\
\hline Missing & $14(1.8)$ & $53(6.6)$ & & \\
\hline \multicolumn{5}{|l|}{ Occupation } \\
\hline Housewife & $344(42.9)$ & $349(43.5)$ & 1.00 & 1.00 \\
\hline Profession/Office worker & $229(28.6)$ & $229(28.6)$ & $0.94(0.70-1.24)$ & $0.87(0.63-1.20)$ \\
\hline Sales/Service & $113(14.1)$ & $100(12.5)$ & $0.84(0.61-1.17)$ & $0.77(0.53-1.10)$ \\
\hline Agriculture/Laborer/Unemployed/Others & $101(12.6)$ & $80(10.0)$ & $0.75(0.53-1.07)$ & $0.69(0.47-1.02)$ \\
\hline Missing & $15(1.9)$ & $44(5.5)$ & & \\
\hline \multicolumn{5}{|l|}{ Monthly household income } \\
\hline$<\$ 1,853^{\mathrm{d})}$ & $103(12.8)$ & $107(13.3)$ & 1.00 & 1.00 \\
\hline$\$ 1,853-\$ 3,706$ & $215(26.8)$ & $224(27.9)$ & $0.99(0.71-1.38)$ & $0.95(0.66-1.39)$ \\
\hline$>\$ 3,706$ & $389(48.5)$ & $329(41.0)$ & $0.79(0.57-1.08)$ & $0.71(0.49-1.03)$ \\
\hline Missing & 95 (11.9) & $142(17.7)$ & & \\
\hline \multicolumn{5}{|l|}{ Marital status } \\
\hline Married & $710(88.5)$ & $674(84.0)$ & 1.00 & 1.00 \\
\hline Unmarried & $20(2.5)$ & $25(3.1)$ & $1.33(0.72-2.44)$ & $1.31(0.68-2.50)$ \\
\hline Divorced/Widowed & $70(8.7)$ & $74(9.2)$ & $1.21(0.84-1.75)$ & $1.25(0.84-1.86)$ \\
\hline Missing & $2(0.3)$ & $29(3.6)$ & & \\
\hline \multicolumn{5}{|l|}{ Alcohol consumption } \\
\hline Non-drinker & $298(37.2)$ & $360(44.9)$ & 1.00 & 1.00 \\
\hline Former drinker & $34(4.2)$ & $45(5.6)$ & $1.06(0.66-1.71)$ & $1.13(0.68-1.88)$ \\
\hline Current drinker & $455(56.7)$ & $373(46.5)$ & $0.61(0.48-0.78)$ & $0.64(0.49-0.82)$ \\
\hline Ever-drinker & $489(61.0)$ & $418(25.7)$ & $1.21(0.62-2.35)$ & $0.68(0.53-0.87)$ \\
\hline Missing & $15(1.9)$ & $24(3.0)$ & & \\
\hline
\end{tabular}


Table 3. Continued

\begin{tabular}{|c|c|c|c|c|}
\hline Variable & $\begin{array}{l}\left.\text { Control }^{a}\right) \\
(n=802)\end{array}$ & $\begin{array}{c}\text { Case } \\
(n=802)\end{array}$ & $\begin{array}{c}\text { Crude OR } \\
(95 \% \mathrm{CI})\end{array}$ & $\begin{array}{c}\text { Adjusted OR } \\
(95 \% \mathrm{CI})^{\mathrm{b})}\end{array}$ \\
\hline \multicolumn{5}{|l|}{ Smoking status } \\
\hline Non-smoker & $541(67.5)$ & $547(68.2)$ & 1.00 & 1.00 \\
\hline Former smoker & $104(13.0)$ & $109(13.6)$ & $0.97(0.66-1.45)$ & $0.97(0.63-1.48)$ \\
\hline Current smoker & $114(14.2)$ & $97(12.1)$ & $0.79(0.55-1.13)$ & $0.82(0.55-1.22)$ \\
\hline Ever-smoker & $218(27.2)$ & $206(25.7)$ & $0.86(0.63-1.19)$ & $0.88(0.62-1.25)$ \\
\hline Missing & $43(5.4)$ & $49(6.1)$ & & \\
\hline
\end{tabular}

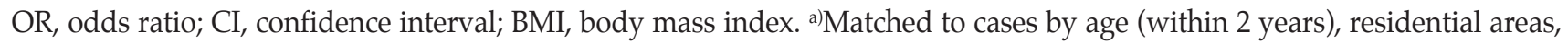

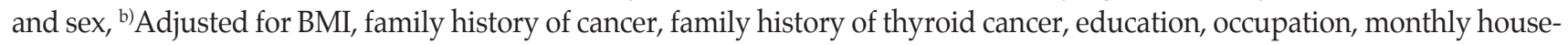
hold income, marital status, alcohol consumption, and smoking status; $R^{2}=0.0711$, ${ }^{c}$ First degree relatives, ${ }^{d} \$ 1=1,079$ Korean won (as of April 26, 2015).

tion was significantly associated with a decreased risk of thyroid cancer.

Overall, these findings are consistent with those of previous studies and reports on the general characteristics and risk factors of thyroid cancer. According to the GLOBOCAN 2012 of the International Agency of Research on Cancer, the age-standardized incidence rate of thyroid cancer worldwide was approximately 3.2 times higher in women than in men: 6.1 per 100,000 and 1.9 per 100,000, respectively [11]. In addition, the incidence data obtained from the Korea National Cancer Incidence Database showed that age-standardized incidence rates per 100,000 were 102.4 in women and 23.0 in men [12], which were approximately 4.5 times higher in women than in men. These results show that thyroid cancer is 3-4 times more common in women than in men. This study also showed that the risk of thyroid cancer was more than 2 times higher in women than in men.

The reasons for the difference in incidence between men and women is unclear. However, estrogen, which is one of the two main female sex hormones, might explain the sex difference in the incidence of thyroid cancer. Several studies have shown that the estrogen levels might be associated with the risk of thyroid cancer. For example, although the frequency of differentiated thyroid cancer (papillary or parafollicular thyroid cancer) in girls was similar to that in boys up to the age of 12 years, with the onset of puberty, it increased in girls [13]. In addition, pregnancy was associated with an increased risk of thyroid cancer $[14,15]$. The onset of puberty and pregnancy are associated with increased levels of estrogen. In contrast, the incidence of thyroid cancer was highest in the late 40s and early 50s (perimenopause) and decreased thereafter (postmenopause) [12]. During these periods, the estrogen levels start to decrease rapidly and level off. As a potential mechanism for the impact of estrogen on the increased risk of thyroid cancer, several experimental studies have shown that $17 \beta$-estradiol (E2, predominant estrogen during reproductive periods) is a potent stimulating agent of both benign and malignant thyroid cells [16-18]. E2 acts via a classical genomic pathway mediated through the estrogen receptors $\alpha$ and $\beta$ (ER $\alpha$ and ER $\beta$ ) and a non-genomic pathway by membrane-associated estrogen receptor [19]. Both pathways are operative in benign and malignant thyroid tissues, even though the detection of ERs in normal thyroid tissues, thyroid adenomas, goiters, and thyroid carcinomas by immunohistochemical staining or reverse transcription polymerase chain reaction varies between $0 \%$ and $100 \%$ of samples $[18,19]$. Nevertheless, the influence of estrogen on the development of thyroid cancer is still unclear. Further detailed studies will be necessary to confirm the association between estrogen and thyroid cancer.

A family history of thyroid cancer was also found to be associated with an increased risk of thyroid cancer. The increased risk of differentiated thyroid cancer was associated with a family history of thyroid cancer from the previous observational studies [20]. In addition, a recent populationbased cohort study with 63,495 first-degree relatives of 11,206 non-medullary thyroid cancer patients reported a three-fold increase over the general population risk (standardized incidence ratio, $2.9 ; 95 \% \mathrm{CI}, 2.4$ to 3.4 ) [21].

Interestingly, in contrast to most of common cancers, this study showed that smoking was associated with a decreased risk of thyroid cancer (ever-smoker vs. non-smoker; OR, 0.62; 95\% CI, 0.44 to 0.86). This finding is consistent with those from previous meta-analyses of case-control studies. In 2003, a pooled analysis of 14 case-control studies reported a reduced risk of thyroid cancer in current smokers [22]. In addition, a recent meta-analysis published in 2014 demonstrated an inverse association in subgroup meta-analysis of case-control studies (ever-smoker vs. non-smoker; OR, 0.79; $95 \%$ CI, 0.70 to 0.88 ) [8]. Similarly, in a pooled analysis of five 
prospective studies, smoking was associated with a lower risk of thyroid cancer in current smokers compared to never smokers (HR, 0.68; 95\% CI, 0.55 to 0.85 ) [7].

Several potential biological mechanisms have been suggested to explain the reduced risk of thyroid cancer in smokers. First, smoking can lead to lower levels of thyroid stimulating hormone (TSH), which plays an important role in the development of thyroid cancer [23]. Second, smoking has an anti-estrogenic effect, which can result in a reduced risk of thyroid cancer [19]. Finally, smokers are less likely to be overweight or obese, which might be associated with an increased risk of thyroid cancer. In 2012, a meta-analysis of seven cohort studies found that overweight and obesity were linked to an $18 \%$ increased risk of thyroid cancer in men and women [6].

In the present findings, higher household incomes were more likely to have a decreased risk of thyroid cancer ( $>\$ 3,706$ vs. $<\$ 1,853 ;$ OR, $0.59 ; 95 \%$ CI, 0.36 to 0.98 ). On the other hand, previous studies have reported that higher socioeconomic status (SES) groups were more likely to show an increased risk of thyroid cancer compared to lower SES groups in the United States [24]. In particular, the incidence of thyroid cancer showed a less pronounced increase in low SES groups (6.7\% per year) than that in the high SES groups (8.6\% per year) in the United States. White Americans showed a steady increase in both the low and high SES groups, while African-Americans and Hispanics with a higher SES showed a more noticeable increase compared to the lower SES groups from 1995 to 2008 [24]. This issue may reflect the limitation in accessing health care services in low SES groups and minorities due to the low health insurance coverage [24]. This discrepancy cannot be explained at present; therefore, further studies will be required.

Additionally, alcohol consumption was found to be significantly associated with a decreased risk of thyroid cancer when the analysis was performed using the control group matched by sex as well as age and residential areas. This finding is consistent with those from the previous pooled analysis of five cohort studies published in 2012 [7]. The possible biological mechanisms include decreased levels of TSH and the direct toxic effects of alcohol consumption [25,26].

This study has several limitations. First, the thyroid cancer cases were not confirmed based on the medical records and chart reviews. The thyroid cancer cases were ascertained by a linkage to the KCCR database based on the ICD-O (code C73), which may lead to ascertainment bias. Therefore, the specific type of thyroid cancer could not be defined in each case. On the other hand, it would be reasonable to assume that most of the cases included in the present study were papillary thyroid cancers because $94.2 \%$ of all incident thyroid cancers from 1997 to 2011 were papillary thyroid cancer according to the Korea National Cancer Incidence Database
[27]. Second, the controls were also not confirmed from their medical records and chart reviews. On the other hand, the possibility of ascertainment bias might be minimal, if any, because the KCCR database covers almost all incident cancer cases, including thyroid cancer nationwide in Korea. Therefore, there would be little likelihood of the thyroid cancer cases being included in the control group of this study. Third, due to a lack of data, this study was unable to investigate the influence of previous exposure to radiation on thyroid cancer, which is a proven risk factor for thyroid cancer. Finally, recall bias might still exist as some data were collected retrospectively. In addition, these findings might not be applicable to the general population because the participants included in this study were recruited from one specific hospital screening center.

To the best of the authors' knowledge, this is the second largest case-control study on the risk factors of thyroid cancer since Kreiger and Parkes's study in 2000 [28]. Therefore, this study provides more precision on this issue than most previous individual studies.

\section{Conclusion}

This hospital-based case-control study found that females, higher BMI, and those with a family history of thyroid cancer were significantly associated with an increased risk of thyroid cancer, whereas ever-smokers, drinkers, and those with higher household incomes were associated with a decreased risk of thyroid cancer. Nevertheless, these findings should be explored in further larger epidemiological studies with a higher level of evidence, such as prospective cohort studies.

\section{Conflicts of Interest}

Conflict of interest relevant to this article was not reported.

\section{Acknowledgments}

This work was supported by grants from the National Research Foundation of Korea (NRF-2015R1D1A1A09058684) and from the National Cancer Center of Korea (NCC1510040). 


\section{References}

1. Stewart BW, Wild CP. World cancer report 2014. Lyon: International Agency for Research on Cancer; 2014.

2. Wartofsky L. Increasing world incidence of thyroid cancer: increased detection or higher radiation exposure? Hormones (Athens). 2010;9:103-8.

3. Ahn HS, Kim HJ, Welch HG. Korea's thyroid-cancer "epidemic": screening and overdiagnosis. N Engl J Med. 2014; 371:1765-7.

4. What are the risk factors for thyroid cancer? [Internet]. Atlanta, GA: American Cancer Society; 2015 [cited 2016 May 1]. Available from: http://www.cancer.org/cancer/thyroidcancer/detailedguide/thyroid-cancer-risk-factors.

5. Schmid D, Behrens G, Jochem C, Keimling M, Leitzmann M. Physical activity, diabetes, and risk of thyroid cancer: a systematic review and meta-analysis. Eur J Epidemiol. 2013;28: 945-58.

6. Zhao ZG, Guo XG, Ba CX, Wang W, Yang YY, Wang J, et al. Overweight, obesity and thyroid cancer risk: a meta-analysis of cohort studies. J Int Med Res. 2012;40:2041-50.

7. Kitahara CM, Linet MS, Beane Freeman LE, Check DP, Church TR, Park Y, et al. Cigarette smoking, alcohol intake, and thyroid cancer risk: a pooled analysis of five prospective studies in the United States. Cancer Causes Control. 2012;23:1615-24.

8. Cho YA, Kim J. Thyroid cancer risk and smoking status: a meta-analysis. Cancer Causes Control. 2014;25:1187-95.

9. Ferlay J, Soerjomataram I, Ervik M, Dikshit R, Eser S, Mathers C, et al. GLOBOCAN 2012 v1.0, Cancer Incidence and Mortality Worldwide: IARC CancerBase No. 11 [Internet]. Lyon: International Agency for Research on Cancer; 2013 [cited 2016 May 1]. Available from: http://globocan.iarc.fr.

10. Allison PD. Survival analysis using the SAS: a practical guide. Cary, NC: SAS Institute Inc.; 1995.

11. Thyroid: ASR (W) per 100,000, all ages [Internet]. Lyon: International Agency for Research on Cancer; 2013 [cited 2016 May 1]. Available from: http://globocan.iarc.fr/old/bar_sex_site. asp ? selection $=27240 \&$ title $=$ Thyroid $\&$ statistic $=2 \&$ populations $=6 \&$ window $=1 \&$ grid $=1 \&$ info $=1 \&$ color $1=5 \&$ color $1 \mathrm{e}=\& \mathrm{col}$ or $2=4 \&$ color $2 \mathrm{e}=\&$ submit $=\% \mathrm{C} 2 \% \mathrm{~A} 0$ Execute $\% \mathrm{C} 2 \% \mathrm{~A} 0$.

12. Jung KW, Won YJ, Kong HJ, Oh CM, Cho H, Lee DH, et al. Cancer statistics in Korea: incidence, mortality, survival, and prevalence in 2012. Cancer Res Treat. 2015;47:127-41.

13. Farahati J, Bucsky P, Parlowsky T, Mader U, Reiners C. Characteristics of differentiated thyroid carcinoma in children and adolescents with respect to age, gender, and histology. Cancer. 1997;80:2156-62.

14. Rossing MA, Voigt LF, Wicklund KG, Daling JR. Reproductive factors and risk of papillary thyroid cancer in women. Am J Epidemiol. 2000;151:765-72.
15. Horn-Ross PL, Canchola AJ, Ma H, Reynolds P, Bernstein L. Hormonal factors and the risk of papillary thyroid cancer in the California Teachers Study cohort. Cancer Epidemiol Biomarkers Prev. 2011;20:1751-9.

16. Zeng Q, Chen GG, Vlantis AC, van Hasselt CA. Oestrogen mediates the growth of human thyroid carcinoma cells via an oestrogen receptor-ERK pathway. Cell Prolif. 2007;40:921-35.

17. Kumar A, Klinge CM, Goldstein RE. Estradiol-induced proliferation of papillary and follicular thyroid cancer cells is mediated by estrogen receptors alpha and beta. Int J Oncol. 2010;36:1067-80.

18. Manole D, Schildknecht B, Gosnell B, Adams E, Derwahl M. Estrogen promotes growth of human thyroid tumor cells by different molecular mechanisms. J Clin Endocrinol Metab. 2001;86:1072-7.

19. Derwahl M, Nicula D. Estrogen and its role in thyroid cancer. Endocr Relat Cancer. 2014;21:T273-83.

20. Xu L, Li G, Wei Q, El-Naggar AK, Sturgis EM. Family history of cancer and risk of sporadic differentiated thyroid carcinoma. Cancer. 2012;118:1228-35.

21. Fallah M, Pukkala E, Tryggvadottir L, Olsen JH, Tretli S, Sundquist K, et al. Risk of thyroid cancer in first-degree relatives of patients with non-medullary thyroid cancer by histology type and age at diagnosis: a joint study from five Nordic countries. J Med Genet. 2013;50:373-82.

22. Mack WJ, Preston-Martin S, Dal Maso L, Galanti R, Xiang M, Franceschi S, et al. A pooled analysis of case-control studies of thyroid cancer: cigarette smoking and consumption of alcohol, coffee, and tea. Cancer Causes Control. 2003;14:77385.

23. Jorde R, Sundsfjord J. Serum TSH levels in smokers and nonsmokers. The 5th Tromso study. Exp Clin Endocrinol Diabetes. 2006;114:343-7.

24. Reitzel LR, Nguyen N, Li N, Xu L, Regan SD, Sturgis EM. Trends in thyroid cancer incidence in Texas from 1995 to 2008 by socioeconomic status and race/ethnicity. Thyroid. 2014;24: 556-67.

25. Balhara YP, Deb KS. Impact of alcohol use on thyroid function. Indian J Endocrinol Metab. 2013;17:580-7.

26. Knudsen N, Bulow I, Laurberg P, Perrild H, Ovesen L, Jorgensen $\mathrm{T}$. Alcohol consumption is associated with reduced prevalence of goitre and solitary thyroid nodules. Clin Endocrinol (Oxf). 2001;55:41-6.

27. Oh CM, Jung KW, Won YJ, Shin A, Kong HJ, Lee JS. Ageperiod-cohort analysis of thyroid cancer incidence in Korea. Cancer Res Treat. 2015;47:362-9.

28. Kreiger N, Parkes R. Cigarette smoking and the risk of thyroid cancer. Eur J Cancer. 2000;36:1969-73. 